\title{
The Effect of Sleep State on Active Thermoregulation in the Premature Infant
}

\author{
ROBERT A. DARNALL JR. ${ }^{(18)}$ AND RONALD L. ARIAGNO \\ University of Virginia School of Medicine, Charlottesville, Virginia and Stanford University School of Medicine, \\ Stanford, California, USA
}

\begin{abstract}
Summary
Alterations in thermoregulatory mechanisms related to sleep state may play an important role in the problems of homeostasis experienced by the premature infant. In the adult, homeothermic regulation of body temperature may be suspended during REM. We measured oxygen consumption $\left(\mathrm{V}_{2}\right)$ in six premature infants 33-35 wk gestation both at thermoneutrality and during a mild thermal stress to determine whether thermoregulatory responses were intact during REM sleep. All infants were studied under radiant warmers. Skin temperature was allowed to fall 7-8 times during a 6-8 h study period while $\dot{\mathrm{V}} \mathrm{O}_{2}, \dot{\mathrm{V}} \mathrm{CO}_{2}$, heart rate and $\mathrm{TcPO}_{2}$ were continuously recorded. Sleep state was scored using EEG, EOG, EMG and behavioral criteria. A total of 1,162 onemin epochs were scored. In all states including $R E M, \mathrm{VO}_{2}$ was significantly higher during the cool periods. The mean increases: $21.5 \%, 23.3 \%, 11.1 \%$ and $5.3 \%$ for Awake, Indeterminate, REM and NREM respectively. When REM and NREM were compared at thermoneutrality, there was no difference in the $\dot{\mathrm{V}} \mathrm{O}_{\mathbf{2}}(\mathbf{8 . 8 0} \pm$ 0.11 and $8.93 \pm 0.15 \mathrm{cc} / \mathrm{kg} / \mathrm{min}$, mean \pm S.E., for REM and NREM, respectively). We conclude that in contrast to the adult, active thermoregulation occurs in the premature infant during REM sleep.
\end{abstract}

\section{Speculation}

In the adult, the reason for temporary poikilothermy during REM sleep is unknown. Some have considered this pheromenon a regression to a phylogenetically primitive condition which is necessary for normal hypothalamic function. Because the newborn period is characterized by profound ontogenic change, it is reasonable to speculate that the difference we observed between the premature and the adult is due to a developmental phenomenon. We further suggest that this developmental process may serve to protect the premature infant during REM sleep from extended periods of poikilothermy.

Alterations in thermoregulatory mechanisms related to sleep state may play an important role in the problems of homeostasis experienced by the premature infant. Very little information is available concerning the effects of arousal state on the control of body temperature. As early as 1941, Day (4) observed a fall in rectal temperature with the onset of sleep in children. The decline in rectal temperature was coincident with increased evaporative water loss and rise in skin temperature indicating that the observed changes were possibly regulated phenomenon.

In the adult, homeothermic regulation of body temperature may be suspended during REM sleep (9). Normal responses to cooling, such as shivering and vasomotor activity, seem to be absent during REM. Likewise, panting, sweating and vasomotor responses to warming also seem to be nonfunctional during REM (11). In contrast to the adult and older child, the newborn spends more time in REM sleep. A suspension of body temperature regulation during extended periods might heavily contribute to the overall poor control of body temperature in these infants.

There has been little reported concerning the ability of the newborn to actively thermoregulate during sleep. The purpose of this study was to investigate the effects of sleep state on the ability of the preterm to increase oxygen consumption in response to a mild thermal stress.

\section{MATERIALS AND METHODS}

Six healthy premature infants of 33-35 wk gestation (weight $=$ $2.11 \pm 0.22 \mathrm{~kg}$, mean + S.D.) were studied between 3 and 17 days of age $(10.8 \pm 3.2$ days, mean \pm S.D. $)$. Informed consent was obtained from the parents and pediatrician of each patient before study. During a 6-8 $\mathrm{h}$ study period, the infants were cared for under an infrared radiant warmer. The infants were fed by gavage every $3 \mathrm{~h}$.

Oxygen consumption $\left(\mathrm{V}_{2}\right)$ and carbon dioxide production $\left(\mathrm{V} \mathrm{CO}_{2}\right)$ were measured with an spen circuit technique described previously (3). Abdominal skin, cheek, rectal, thigh and air temperatures were measured with thermistors (YSI, 400 series). In some patients, transcutaneous oxygen tension $\left(\mathrm{TcPO}_{2}\right)$ was measured with a Litton Oxymonitor. Heart and respiratory rate were measured with a clinical impedance type monitor (Perinatal Systems, Inc.).

The analog outputs from the gas analyzers, telethermometers, transcutaneous oxygen monitor, and impedance monitors were digitized at $1 \mathrm{~Hz}$, and averaged every 15 sec with a microcomputer (Cromemco Z2D). From the averaged data, on line calculations of $\dot{\mathrm{VO}}_{2}$ and $\dot{\mathrm{V}} \mathrm{CO}_{2}$ were made. All data was displayed and updated every $15 \mathrm{sec}$ on a cathode ray terminal and simultaneously stored on floppy disk for later analysis.

EKG, EOG, EEG and EMG were continuously monitored using standard bipolar electrodes. Respiratory rate and pattern were measured using piezoelectric crystals attached to the chest and abdomen. These parameters were recorded on a Grass polygraph.

After a period of stabilization, when abdominal skin temperature was between $36.0-37.0^{\circ} \mathrm{C}$, rectal temperature was between $36.5-37.5^{\circ} \mathrm{C}$. The oxygen consumption recordings were relatively stable, the skin temperature was allowed to fall 4-10 times during a 6-8 $\mathrm{h}$ study period. During the cooling periods, the mean rate of fall of abdominal skin temperatures was $0.2 \mathrm{C} / \mathrm{min}$ and the mean duration of the cooling periods was $13.0 \mathrm{~min}$. Sleep state was scored independently for the entire study period without regard for changes in body temperature, using modified standard criteria (1). States were defined as REM, NREM, Indeterminate (IND) or Awake. The record was then divided into warm and cool periods. A cool period was defined as the period beginning with a drop in abdominal skin temperature and ending when the temperature again began to rise. The baseline periods between cooling episodes were defined as warm periods.

Each 1-min epoch was scored for state, temperature (warm or cool), oxygen consumption and heart rate. Warm epochs were 
then compared to cool epochs to determine the effects of state on $\dot{\mathrm{VO}} \mathrm{O}_{2}$ and heart rate.

Data was analyzed using a general linear models procedure (6). State and temperature were considered independent variables and $\dot{\mathrm{VO}}_{2}$ and heart rate were considered dependent variables.

\section{RESULTS}

From the combined recordings from all six infants, 8801 -min epochs were analyzed for $\mathrm{VO}_{2}$ and 1,143 were analyzed for heart rate. Of the 880 epochs of $\dot{\mathrm{VO}} 2$ data, 381 were scored as warm and 499 were scored as cool. Of the 1,143 epochs of heart rate data, 609 , were scored as warm and 534 as cool.

As expected, when all states were combined, the overall $\dot{\mathrm{V}}_{2}$ and heart rate were significantly higher during the cool periods when compared to warm periods. The $\dot{\mathrm{VO}}_{2}$ was $8.94 \pm 0.09 \mathrm{cc} /$ $\mathrm{kg} / \mathrm{min}$ (mean \pm S.E.) and $10.33 \pm 0.8 \mathrm{cc} / \mathrm{kg} / \mathrm{min}$ for the warm and cool periods, respectively $(P<0.0001)$. The heart rate was $151.8 \pm 0.70$ for warm periods and $156.2 \pm 0.75$ for cool periods, $(P<0.0001)$.

When warm and cool periods were combined, the $\mathrm{VO}_{2}$ was significantly higher in the awake state $(10.89 \pm 0.14 \mathrm{cc} / \mathrm{kg} / \mathrm{min} P$ $<0.0001)$ compared to the other states. During. indeterminate sleep, $\dot{\mathrm{VO}}_{2}$ was significantly higher than either during REM or NREM sleep $(9.79 \pm 0.14 \mathrm{cc} / \mathrm{kg} / \mathrm{min}, P<0.0005$ and $P<0.0025$ for REM and NREM respectively). $\mathrm{VO}_{2}$ during NREM was not significantly different from the $\mathrm{VO}_{2}$ during REM $(9.17 \pm 0.10$ and $9.29 \pm 0.08 \mathrm{cc} / \mathrm{kg} / \mathrm{min}$ for REM and NREM, respectively, $P>$ $0.3)$.

Similarly, when warm and cool periods were combined, the heart rate during wakefulness was significantly higher than heart rate during all states of sleep, $(174.6 \pm 1.0, P<0.0001)$. Heart rates during IND, REM and NREM sleep were not significantly different from one another $(151.2 \pm 1.1,148.9 \pm 0.0,148.8 \pm 0.6)$ for IND, REM and NREM respectively.

Table 1 contains oxygen consumption data grouped by temperature and state. In all states $\dot{\mathrm{VO}}_{2}$ rose significantly when the infant was exposed to a mild thermal stress. When the data were examined for each infant separately, similar results were obtained. It is of note that all six infants increased $\mathrm{VO}_{2}$ in response to cooling during REM.

Table 2 describes the results of the Duncan's multiple range test (14) for oxygen consumption. This test was chosen to minimize the bias encountered when multiple tests are done on sample means. Means with the same letter were not significantly different. Although the infants were warm, there was no differences in $\dot{\mathrm{VO}_{2}}$

Table 1. Oxygen consumption grouped by temperature and sleep state

\begin{tabular}{lcccc}
\hline & Awake & IND & REM & NREM \\
\hline Warm & $9.83 \pm 0.25^{1}$ & $8.77 \pm 0.22$ & $8.80 \pm 0.11$ & $8.93 \pm 0.15$ \\
Cool & $11.95 \pm 0.15$ & $10.81 \pm 0.18$ & $9.78 \pm 0.11$ & $9.40 \pm 0.15$ \\
$P$ & $<0.0001$ & $<0.0001$ & $<0.0001$ & $<0.025$ \\
\hline
\end{tabular}

${ }^{1}$ Mean \pm S.D., $(\mathrm{cc} / \mathrm{kg} / \mathrm{min}) ;$ IND, Indeterminate sleep; REM, REM sleep; and NREM, NREM sleep.

Table 2. Duncan's multiple range test for oxygen consumption

\begin{tabular}{crrll}
\hline Group & Mean & \multicolumn{1}{c}{$N$} & \multicolumn{2}{c}{ Condition } \\
\hline A & $11.95^{1}$ & 111 & awake & cold \\
B & 10.81 & 72 & IND & cold \\
C & 9.83 & 38 & awake & warm \\
C & 9.78 & 205 & REM & cold \\
C & 9.40 & 111 & NREM & cold \\
D & 8.93 & 112 & NREM & warm \\
D & 8.80 & 183 & REM & warm \\
D & 8.77 & 48 & IND & warm \\
\hline
\end{tabular}

${ }^{1} \dot{\mathrm{VO}}_{2}$ (cc/kg/min); IND, Indeterminate sleep; REM, REM sleep; and NREM, NREM sleep. when IND, REM and NREM were compared. The largest increases in $\mathrm{VO}_{2}$ occurred when the infants were stressed during indeterminate sleep and while awake. The increases in $\dot{\mathrm{VO}}_{2}$ during REM and NREM sleep were of equal magnitude.

\section{DISCUSSION}

Until recently, it was a common belief that homeotherms maintain body temperature within a narrow range as a result of continuous regulation. There is mounting evidence in the literature, however, that homeothermic regulation is suspended during REM sleep. Parmeggiani, et al. $(9,10)$ have convincingly shown in the adult cat and rabbit that REM sleep inhibits normal thermoregulatory responses to environmental stimuli. Glotzbach and Heller (5) have demonstrated similarly in the kangaroo rat that cooling the hypothalamus fails to illicit the normal increase in $\mathrm{VO}_{2}$ when the animal is in REM sleep. Ogawa, et al. (8) have shown that the sweat rate of the adult human decreases in a warm environment during REM sleep. In the adult, body temperature and rate of change is very close to that of a pontine poikilothermic preparation (2).

In contrast to the adult animal and human, very little is known about the effect of sleep on active thermoregulation in the newborn. A large surface area of body mass ratio, increased permeability of the skin, and small radii of curvature place the newborn in a vulnerable position with regard to defense against the thermal environment. A further inability to respond to thermal changes during REM, as occurs in the adult, would be an important additional factor contributory to poor thermal homeostasis.

Our data suggest that, unlike the adult, the ability of the premature to increase $\dot{\mathrm{VO}}_{2}$ in response to a thermal stress is intact during REM sleep. These results are in agreement with those of Stothers and Warner $(15,16)$ who found that $\mathrm{VO}_{2}$ increased in fullterm infants during both REM and NREM sleep when the infants were moved from thermoneutrality into a cool environment. Although early investigators generally did not take sleep state into account, it is of interest that these studies demonstrated that even small premature infants increased $\mathrm{VO}_{2}$ in response to cooling. Because these infants spend most of their sleep time in REM (50-80\%), it is likely that some of these data were collected during REM sleep, and further support the hypothesis that thermoregulation is intact during REM in the newborn.

While other investigators have demonstrated a higher $\mathrm{VO}_{2}$ during REM compared to NREM, at thermoneutrality, we could find no significant difference. Scopes and Ahmed (13) found that $\mathrm{VO}_{2}$ increased $16 \%$ when the infant changed states from "deep" to "light" sleep. More recently Stothers and Warner $(15,16)$ demonstrated that when NREM period preceeded a REM period, $\mathrm{VO}_{2}$ increased by $9.2 \%$. This is consistent with the report of Kairam, et al. (7) who showed a $9.4 \%$ increase in $\dot{\mathrm{V}}_{2}$ when sleep state changed from NREM to REM.

The reasons for the discrepancy is not clear, although there are two factors that may contribute. First, the direction of state change may be important. The studies cited above looked at changes from NREM to REM sleep. We did not take the direction of change into account. When Stothers and Warner analyzed their data irrespective of the directions of change, the $\mathrm{V}_{2}$ during REM was $5.40 \mathrm{cc} / \mathrm{kg} / \mathrm{min}$ compared to $5.22 \mathrm{cc} / \mathrm{kg} / \mathrm{min}$ during NREM. Although these authors found this difference to be significant, the difference is very small and very close to the uncertainty of the measuring equipment.

Second, most investigators have used purely behavioral criteria to define sleep states. These methods depend on the observations of rapid eye movements, body and irregular respirations to define REM. We used the method of Anders, et al. (1) modified for use in the premature infant. This method depends heavily on EEG, EOG and EMG criteria. Using these criteria, for example, periodic breathing can be identified during periods of NREM sleep (12). Inasmuch as body movements and breathing patterns may effect $\mathrm{VO}_{2}$, this may have contributed the differences in the observed data. 
Our findings, that the premature infant is different than the adult and is able to increase $\mathrm{VO}_{2}$ in response to cooling during REM was not expected. The reasons why the premature should respond differently than the adult are unclear.

In the adult, REM sleep is fractionated into many short episodes. If it were not so, the organism might be endangered by hypothermia or hyperthermia depending on the ambient temperature (10). The reason for poikilothermy during REM is unknown. Parmeggiani (9) has suggested that this phenomenon might be considered a regression to a phylogenetically primitive condition which probably involves a process that is necessary for normal function of the hypothalamus.

Because the newborn period is characterized by profound ontogenic change in the central nervous system, it is reasonable to assume that the differences we observed in the premature are due to a developmental phenomenon. We suggest that this developmental process may serve to protect the premature infant during REM sleep from long periods of poikilothermy that would otherwise occur.

\section{REFERENCES AND NOTES}

1. Anders, T., Emde, R., and Parmelee, A. (Eds.): A Manual of Standardized Terminology, Techniques and Criteria for Scoring of States of Sleep and Wakefulness in Newborn Infants, U.C.L.A. Brain Information Service, B.R.I. Publications Office, (Los Angeles, California, 1971).

2. Aschoff, J.: Circadiane Periodike als Grundlage des Schlaf-Wach-Rhythmus. In: Ermudung, Schlaf and Traum pp. 59-98. (Fischer, Frankfurt, Germany 1971).

3. Darnall, R. A. and Ariagno, R. L.: Minimal oxygen consumption in infants cared for under overhead radiant warmers compared with conventional incubators. J. Pediatr., 93: 283 (1978).

4. Day, R.: Regulation of body temperature during sleep. Am. J. Dis. Child., 61: 734 (194I).

5. Glotzbach, S. F. and Heller, H. C.: Central nervous system regulation of body temperature during sleep. Science, 194: 537 (1976).

6. Goodnight, J. H. and Harvey, W. R.: Least square means in the fixed effects general linear model. SAS Technical Report R-103, (Raleigh: SAS Institute, Inc., 1978).

7. Kairam, R., Schulze, K., Koenigsberger, M., and James, L. S.: The effects of changing sleep state on autonomic functions in the newborn. Pediatr. Res., 13: 498 (1979).

8. Ogawa, T., Satoh, T., and Takagi, K.: Sweating during sleep. Jap. J. Physiol., 17: 135 (1967).

9. Parmeggiani, P. L.: Interaction between sleep and thermoregulation, waking and sleeping. I: 123 (1977).

10. Parmeggiani, P. L., Franzini, C., Lenzi, P., and Cianzi, T.: Inguinal subcutaneous temperature changes in cats sleeping at different environmental temperatures. Brain Res. 33: 397 (1971).

11. Parmeggiani, P. L. and Rabini, D.: Shivering and panting during sleep. Brain Res. 6: 789 (1967).

12. Rigatto, H., Kalapes, Z., Leahy, F. N. Durand, M., Maccallum, M., and Cates, D.: Chemical control of respiration frequency and tidal volume during sleep in preterm infants. Res. Phys., 41: 117 (1980).

13. Scopes, J. W. and Ahmed, I.: Minimal rates of oxygen consumption in sick and premature newborn infants. Arch. Dis. Child., 41: 407 (1966).

14. Steel, R. G. D. and Torrie, J. H.: Principles and procedures in statistics. p. 481. (McGraw Hill, New York, 1960).

15. Stothers, J. K. and Warner, R. M.: Oxygen consumption and sleep state in the newborn. J. Physiol., 269: 57 (1977).

16. Stothers, J. K. and Warner, R. M.: Oxygen consumption of the newborn infant in a cool environment, measured within regard to sleep state. J. Physiol., 273: 16 (1977).

17. The authors would like to thank Roger Baldwin, Susan Coons, and Margaret Bodekker of the Stanford SIDS group for helping with the studies and scoring the sleep recordings. Our thanks are also extended to Christian Guilleminault for his helpful comments and review of the polygraphs, to Donald Kaiser for the statistical analysis, and to the nurses of the Premature Research Center, without whose help, these studies could not have been performed.

18. Requests for reprints should be addressed to: Dr. Robert A. Darnall, Jr., Department of Pediatrics, Box 386, University of Virginia Medical Center, Charlottesville, VA 22908.

19. This research was supported by grant RR-81 from the General Clinical Research Centers Program of the Division of Research Resources, National Institutes of Health, and grant HD-00049 from the National Institutes of Health.

20. Received for publication September 8, 1981.

21. Accepted for publication November 13, 1981. 